\title{
Functional Results of Use of Mesh in Orthopaedic Oncology Surgery (Long Term Follow Up)
}

\section{Manish R Shah ${ }^{1}$, Manisha M Shah ${ }^{2}$, Yaswanth Teja Vattikuti ${ }^{3}$, Sarvang M Desai ${ }^{4}$, Paresh P Golwala ${ }^{5}$}

'MBBS, MS (Orthopaedics), Associate Professor, Department of Orthopaedics, Dhiraj Hospital, Smt. B. K. Shah Medical lnstitute and Research Centre, Sumandeep Vidyapeeth Deemed to be University, Waghodia, Vadodara - 391760, Gujarat, India; ${ }^{2}$ MBBS, MD (Pathology), Assistant Professor, Department of Pathology, Medical College and SSG Hospital, Vadodara - 39176o, Gujarat, India; ${ }^{3}$ MBBS, 3rd Year Resident, Department of Orthopaedics, Dhiraj Hospital, Smt. B. K. Shah Medical Institute and Research Centre, Sumandeep Vidyapeeth Deemed to be University, Waghodia, Vadodara - 39176o, Gujarat, India; 4Professor, MBBS MS (Orthopaedics), Department of Orthopaedics, Dhiraj Hospital, Smt. B. K. Shah Medical Institute and Research Centre, Sumandeep Vidyapeeth Deemed to be University, Waghodia, Vadodara - 39176o, Gujarat, India; 5 Professor, MBBS MS (Orthopaedics), Head of Department, Department of Orthopaedics, Dhiraj Hospital, Smt. B. K. Shah Medical lnstitute and Research Centre, Sumandeep Vidyapeeth Deemed to be University, Waghodia, Vadodara - 39176o, Gujarat, India.

\section{ABSTRACT}

Background: Diagnosis of a malignant bone tumour has been confusing to a general orthopaedic surgeon. Advancement in radio and chemotherapy fields and better diagnostic modalities helped a lot in the improvement of results of limb salvage surgery. In limb salvage surgeries after tumour resection, replacement with mega-prosthesis is one of the standard methods. To improve functional outcomes, we have used mesh in our study.

Objectives: To evaluate the results of the use of mesh in limb salvage surgeries done for malignant bone tumours by comparing the range of movements with a group of patients in which mesh was not used. The objective is to assess the clinical and functional outcomes of the patients.

Methods: A retrospective study of 19 patients was carried out. We included patients with a minimum follow up of 6 months. The study includes all common regions of the body affected by the malignant bone tumour (lower end femur, upper-end tibia, upperend femur and upper-end humerus) operated by limb salvage surgery and mega-prosthesis replacement. Two study groups, one without mesh and one with the use of mesh were compared. We have used mesh in primary reconstruction surgery.

Results: Results were evaluated by the Musculo Skeletal Tumour Society (MSTS) scoring system showed a good range of movements in terms of Shoulder abduction (for Proximal humerus replacement) [Figure 1,2\&3] and knee extension.

Conclusion: Use of mesh induces fibrosis and provides anchorage to soft tissues and muscles in limb salvage surgery. Thus achieves a good range of active movements and can lessen the time for immobilization. Thus it helps psychosocial rehabilitation of the family and society, 5 .

Key Words: Orthopaedic oncology surgery, Limb salvage surgery, Mega-prosthesis, Bone cancer surgery, Mesh in Orthopaedic Oncology, Psychosocial rehabilitation in bone cancer

\section{INTRODUCTION}

The diagnosis of the malignant bone tumour has been confusing to a general orthopaedic surgeon. Advancement in radio and chemotherapy fields and better diagnostic modalities helped a lot in the improvement of results of limb salvage surgery. Three main components of limb salvage surgery include (a) tumour resection, (b) replacement with megaprosthesis and, (c) soft tissue reconstruction. Soft tissue re- construction is a major part after replacement and adherence of muscle to the metallic prosthesis is the key to achieve the movements after such surgeries. ${ }^{1,2}$

There are various methods to achieve adhesion of muscles to metallic prostheses like Hydroxyapatite coating at sites of major tendon insertion, use of a bone plug, and the use of mesh $^{1,10}$. Our retrospective study of the use of mega-prosthesis in limb salvage (19 patients) includes different regions like distal femur, proximal tibia, and upper-end humerus. We

\section{Corresponding Author:}

Dr. Yaswanth Teja Vattikuti, MBBS, 3rd Year Resident, Department of Orthopaedics, Dhiraj Hospital, Smt. B. K. Shah Medical Institute and Research Centre, Sumandeep Vidyapeeth Deemed to be University, Waghodia, Vadodara - 391760, Gujarat, India. Phone: 6359562789; Email: yaswanth.teja1991@gmail.com

ISSN: 2231-2196 (Print)

Received: 24.07 .2020
ISSN: $0975-5241$ (Online)

Revised: 28.09 .2020
Accepted: 07.11 .2020
Published: 14.12 .2020 
used mesh in some cases and compared the results of the movements. We have calculated and compared the results by the MSTS system in both groups. ${ }^{7}$ Despite extensive research, we could not find such a study showing comparison and long-term follow-up of such kind involving different regions of the body. ${ }^{3-5}$

Usually, malignant bone tumour affects young patients, who are the main earning members of the family. Giving better outcomes will ultimately enhance their earning capacity and will be of definitely help for society. It will ultimately help in the psychosocial rehabilitation of the family and society as a whole..$^{5-7}$

Based on this background, we aimed to evaluate the results of the use of mesh in Orthopaedic oncology surgeries in terms of movements in comparison to surgeries where mesh was not used. The objective is to assess the functional and clinical outcomes of the patients. Mesh was used in all surgeries done after 2016, January in limb preservation surgeries involving commonly involved areas like lower end femur, upper-end tibia, upper femur and upper humerus.

\section{MATERIALS AND METHODS}

A retrospective study of 19 patients with a minimum follows up of 6 months (ranged from 7 months to 5.5 years with a mean of 4.4 years) was carried out in a rural tertiary care cancer hospital in the department of Orthopaedic Oncology. Consents from patients and IRB approval were taken.

Patients operated from June 2014 to March 2020 are taken in the study. The mesh was used after January 2016. So, a comparison could be done regarding the advantage of the use of the mesh. Distributions of various regions are shown in Table 1. Inclusion and exclusion criteria are mentioned in Table 2.

\section{Table 1: Region wise distribution of cases}

\begin{tabular}{clcc} 
Sr. No. & Region involved & $\begin{array}{c}\text { Number (June } \\
\text { 2014 to January } \\
\text { 2016) }\end{array}$ & $\begin{array}{c}\text { Number } \\
\text { (January } \\
\text { 2016 to } \\
\text { March 2020) }\end{array}$ \\
\hline 1 & Proximal femur & 01 & 03 \\
2 & Distal femur & & 06 \\
3 & Proximal tibia & 02 & 04 \\
4 & Upper Humerus & 01 & 02 \\
& Total & 04 & 15 \\
\hline
\end{tabular}

Table 2: Inclusion and exclusion criteria

\begin{tabular}{|c|c|}
\hline Inclusion criteria & Exclusion criteria \\
\hline $\begin{array}{l}\text { Patients operated for limb } \\
\text { salvage surgeries. }\end{array}$ & $\begin{array}{l}\text { Patients who gave a history of } \\
\text { allergy to mesh or had compli- } \\
\text { cations related to mesh used in }\end{array}$ \\
\hline $\begin{array}{l}\text { Patients who came for follow } \\
\text { up at least at } 6 \text { months. }\end{array}$ & abdominal surgery (1-patient). \\
\hline
\end{tabular}

\section{SURGICAL TECHNIQUE}

Out of 19 cases, the mesh was used in 15 cases. 4 patients were of the upper-end tibia, 2 were of the upper-end humerus and 6 were of the lower end femur and 3 were of upper-end femur mega-prosthesis replacements. Prolene material mesh of $15 \times 15 \mathrm{~cm}$ size was used [Figure 4, 5 and 6].

In all cases, standard oncology resection principles were followed. MRI measurements after pre-operative chemotherapy were taken and $3 \mathrm{~cm}$ wide marginal resection was done. Frozen section from the proximal canal was done in all cases and surgery was done only after confirmation of negative margins. In all cases, postoperative specimens were reported as margin free $(8-10 \mathrm{~mm})$. Postoperative chemotherapy was given as per the advice of an Onco-physician (Figure 1,2 and 3).

In cases of upper-end tibia replacement, a plug of bone was kept at the patellar tendon insertion site after tightly wrapping the mesh around the implant (by Ethibond no.5 or Fiber wire no. 2 suture material). So, a tight sleeve of mesh is created between the bony plug and patellar tendon.

For upper-end humerus, the mesh was put on the glenoid. Its edges were sutured with a labrum. The pear shape of the glenoid was cut and the outer margins were wrapped around the head and rotator cuff margins were sutured with Ethibond No. 5. Greater tuberosity tip was not excised in cases not involving it by the tumour (following principles of wide marginal excision). In cases with involvement of greater tuberosity, rotator cuff tendon was attached directly to the holes provided in the implant with mesh as an interface.

For, Proximal femur replacement same principle as proximal humerus replacement was applied. In the cases in which we have preserved the tip of the greater trochanter, it was sutured with the implant holes with mesh in-between. In the cases in which the bone was not preserved, the abductors or the preserved muscles and iliopsoas tendon were sutured with the tip of the greater trochanter (prosthesis) and lesser trochanter site (prosthesis) ${ }^{1}$.

In cases of lower end femur replacement; tightly wrapped mesh was sutured with the innermost layer of preserved muscles, and the knee was kept in flexion to keep muscles in optimum tension. Antibiotics were given intravenously for five days till the drain was removed (maximum 5 days). Oral 
antibiotics were continued for around 10 days further (till suture removal). Splintage was given to immobilize the part to induce fibrosis for around 4 to 6 weeks. During the time of immobilization period, static physiotherapy was advised followed by dynamic exercises after around 6 weeks. In all patients with lower limb involvement, partial weight-bearing was started from the next day of surgery with a walker. Use of a tripod/ walking stick was advised after 8-10 weeks.

\section{RESULTS}

The cases which were operated by mesh (operated after January 2016) showed a good range of movements in terms of Shoulder abduction (for Proximal humerus replacement) [Figure 1,2\&3] and knee extension [Figure $3 \& 4$ ] (less than 10 degrees of FFD) (for Proximal tibial and distal tibial replacements).

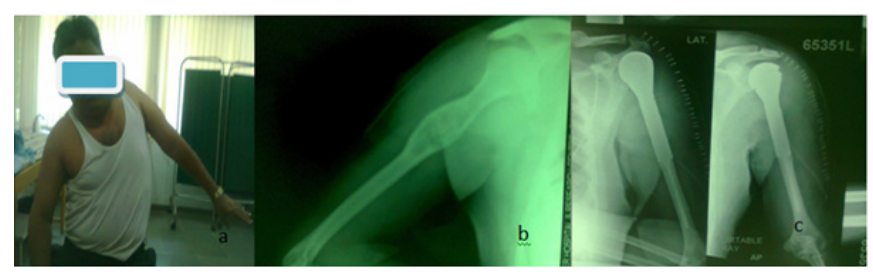

Figure 1: Represents case operated without mesh); (a) Post operative movement, (b) Pre operative X-ray, (c) Post operative $\mathrm{X}$-ray.

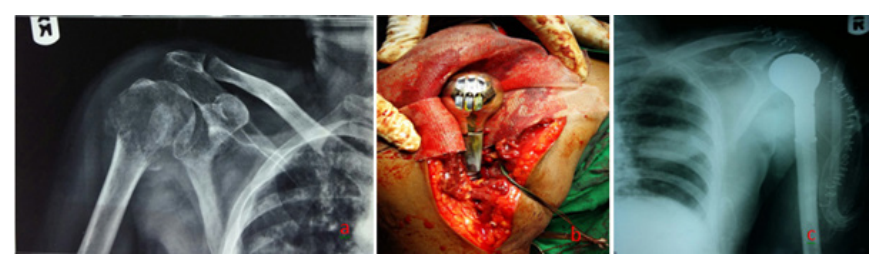

Figure 2: Represents case with mesh; (a) Pre operative X-ray, (b) Intra operative photograph, (c) Post operative X-ray.

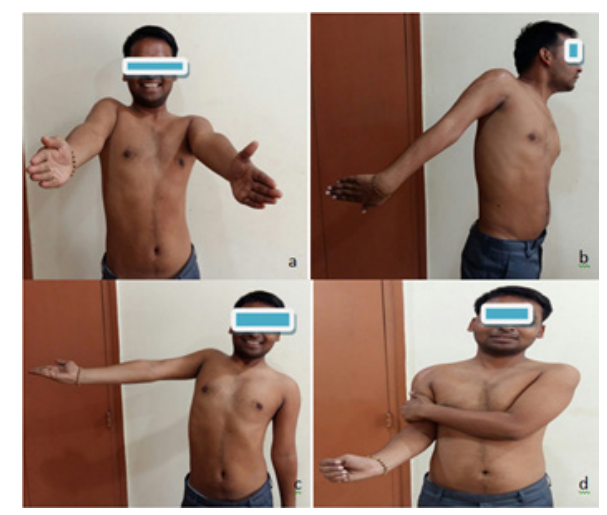

Figure 3: Represents case operated with mesh. (a) Forward flexion, (b) Extension, (c) Abduction, (d) External rotation.
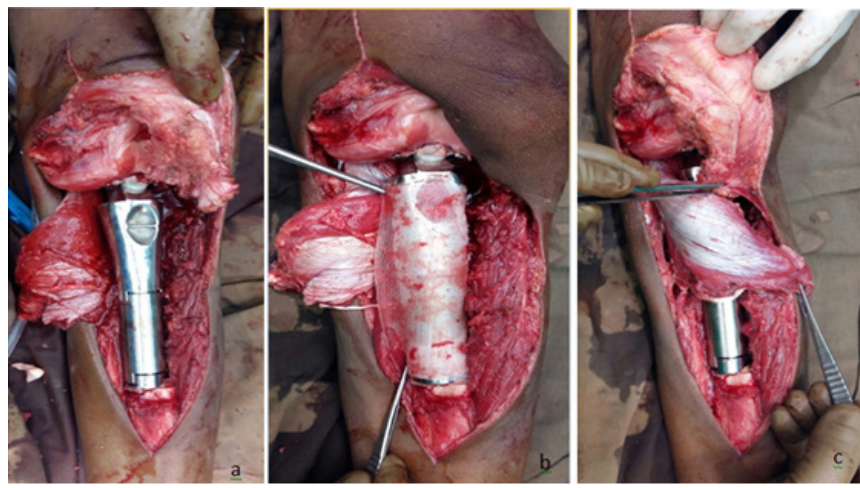

Figure 4: Showed use of mesh in Proximal tibia replacement. (a)Prosthesis in situ, (b)mesh wrapped around prosthesis, (c) gastrocnemius flap around the mesh.
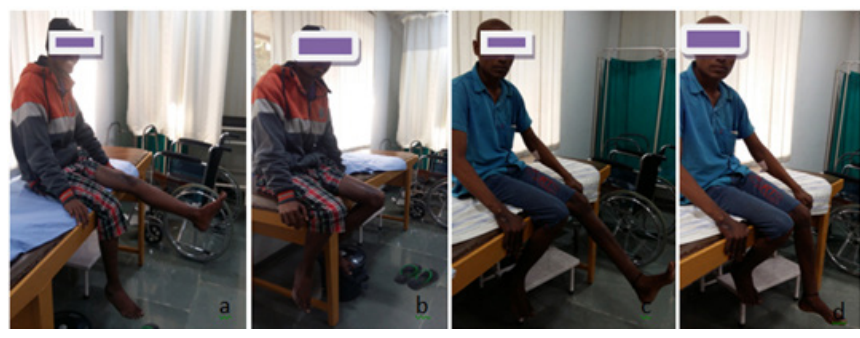

Figure 5: Showed results of the movements in case with and without mesh. (a) \& (b) with mesh; (c) \& (d) without mesh.

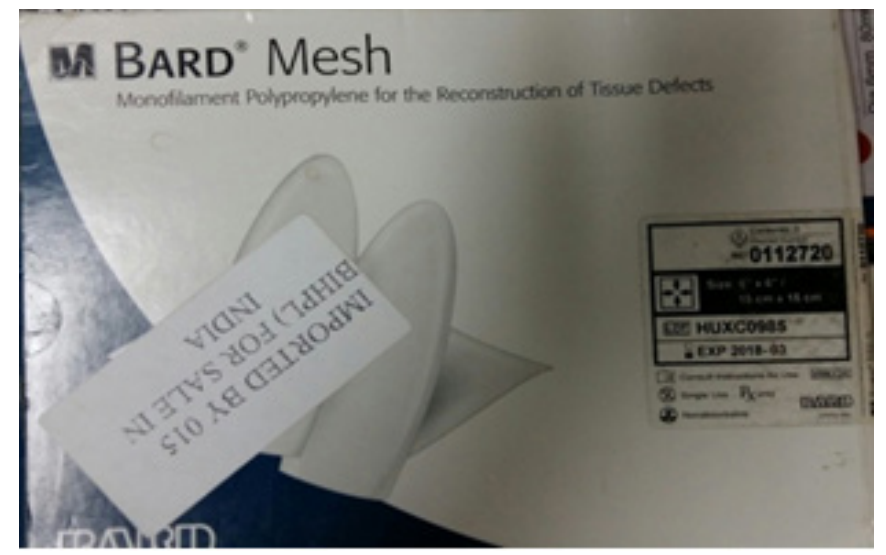

Figure 6: Mesh used for repair.

Results found on evaluation by the MSTS score system are shown in Table 3 and 4.

Table 3: Results found as per MSTS scoring system

\begin{tabular}{lcc} 
Region involved & $\begin{array}{c}\text { MSTS score } \\
\text { (without mesh) } \\
\text { (Maximum 35) }\end{array}$ & $\begin{array}{c}\text { MSTS score } \\
\text { (with mesh) } \\
\text { (Maximum 35) }\end{array}$ \\
$\begin{array}{l}\text { Knee (Upper tibia \& } \\
\text { Lower femur) }\end{array}$ & 13 & 23 \\
Upper-end femur & 14 & 25 \\
Upper-end humerus & 9 & 20 \\
\hline
\end{tabular}


Region-wise distribution of particular MSTS score is displayed in Table 4.

\begin{tabular}{|c|c|}
\hline Involved region & MSTS score \\
\hline $\begin{array}{l}\text { Knee } \\
\text { (Upper tibia \& Lower femur) }\end{array}$ & $\begin{array}{l}\text { - Functional activity } \\
\text { - Emotional acceptance }\end{array}$ \\
\hline Upper-end femur & - Hip abduction \\
\hline Upper-end humerus & $\begin{array}{l}\text { - Deformity (ROM)/Stability } \\
\text { - Shoulder abduction strength } \\
\text { - Combined movements }\end{array}$ \\
\hline
\end{tabular}

Follow-up in our study ranged from 7 months to 5.5 years with a mean of 4.4 years. In further evaluation, we are now planning to do a prospective study of starting early mobilization at 4 weeks instead of 6 to 8 weeks.

\section{DISCUSSION}

Preservation of limb is the best option for bone malignancies. Apart from limb salvage, good function preservation is important for better living. In the last decade, there are new advancements in techniques for limb saving surgeries. We had 5 female and 14 male patients (total 19) in our study. The age group is from 9 years to 70 years with a mean age from 15 to 25 years. We have started using mesh in January 2016 in the department of Orthopaedic oncology tertiary cancer care hospital.

After an extensive search, we could find a few relevant references. ${ }^{3,4,8}$ Some have used mesh in revision tumour surgeries (after complication e.g. dislocation of the prosthesis). ${ }^{3}$ Another author surveyed the use of mesh in proximal humerus surgery. ${ }^{4}$

There were 3 patients with upper-end humerus involvement, 4 with upper femur involvement, 6 were with lower end femur involvement, and 6 with upper tibia involvement (total 19). We have evaluated our results as per the MSTS rating system at the time of follow-ups of 6months, 12 months and, 24 months. Apart from that, we have considered an active extension of less than $10^{\circ}$ as a good functional result for lower extremity surgeries and abduction of more than $60^{\circ}$ as a good functional result for upper extremity surgeries (keeping in mind requirements of activities of daily living), It is seen that, patients in whom we have not used mesh, were able to get movements of knee extension with around 20 degrees of extension deficit. The extension deficit/lag was less or there was a full extension of the knee joint in the patients operated with mesh ${ }^{8}$. In all upper tibial replacement cases, medial gastrocnemius flap was done as a standard manner as described in textbooks. ${ }^{2}$
Hydroxyapatite coated implants are much more expensive than non coated implants. By cutting down the cost of the implant, we reduce the cost of surgery. Mobilization of joint occurs only by the soft tissues in the case where the mesh was not used. Mesh provides anchorage to soft tissues. By making a tight sleeve of mesh around the implant it works like a periosteum on which muscles and other soft tissues get the attachment. Mesh is tightly wrapped around the implant and kept in place by sutures passed through it and the holes provided in the implant at proper anatomical sites. ${ }^{2}$

Infection is always worrisome complication for such surgeries. ${ }^{8}$ No foreign body reaction or infection due to the mesh was found in our study. One complication of flap necrosis in upper tibia replacement was tackled by revision flap after a week of the first surgery. Neither foreign body soft tissue reaction nor signs of infection noted in the same case. Despite fewer numbers, we have included all commonly involved regions by bone malignancies. It can be considered a positive point for our study. Through our follow-up is long, still longer follow-up will help us.

\section{CONCLUSION}

Use of mesh induces fibrosis and provides anchorage to soft tissues and muscles in limb salvage surgery. Thus achieves a good range of active movements and can lessen the time for immobilization. Thus it helps psychosocial rehabilitation of the family and society.

\section{ACKNOWLEDGEMENT}

We acknowledge the patients, their family members, hospital staff, and all others who directly or indirectly participated in the study.

\section{Conflict of Interest: None}

\section{Source of Funding}

No funding received from any source for the study.

\section{AUTHOR CONTRIBUTION}

\begin{tabular}{|c|c|c|}
\hline Sr. No. & Name of Author & Contribution \\
\hline 1 & $\begin{array}{l}\text { Dr Manish R. Shah } \\
\text { (First Author) }\end{array}$ & $\begin{array}{l}\text { Manuscript Preparation, } \\
\text { Data Acquisition, } \\
\text { Data Analysis, Statistical } \\
\text { Analysis, } \\
\text { Concept, Design }\end{array}$ \\
\hline 2 & $\begin{array}{l}\text { Dr Manisha M. Shah } \\
\text { Dr. Yaswanth Teja Vat- } \\
\text { tikuti (Corresponding } \\
\text { Author) }\end{array}$ & $\begin{array}{l}\text { Manuscript Preparation, } \\
\text { Data Acquisition, } \\
\text { Literatur Search, Clinical } \\
\text { Studies }\end{array}$ \\
\hline 3 & $\begin{array}{l}\text { Dr Sarvang M. Desai } \\
\text { Dr. Paresh P Golwala }\end{array}$ & Manuscript Editing, Review \\
\hline
\end{tabular}




\section{REFERENCES}

1. Martin M, Malawer, James C. Wittig, Jackob Bickels: Operative Techniques in Orthopaedic Surgical Oncology. Sam W. Wiesel (ed: Wolters Kluwer | Lippincott Williams \& Wilkins, United States, 2012. http://solution.Iww.com/operativetechniquesoncology.

2. Puri A, Agarwal M. Use of polypropylene mesh to stabilize skeletal reconstructions. after resection for bone tumours. J Surg Oncol 2007; 2:158-60.

3. Wang B, Wu Q, Liu J, Yang S, Shao Z. Endoprosthetic reconstruction of the proximal humerus after tumour resection with polypropylene mesh. Int Orthop 2015, 39:501-6.

4. Umari A. A review on quality of life in cancer patients: an Indian scenario in the next 20 years. Int J Cur Res Rev. 2017; 46(9): 234-236.
5. Uehara K, Ogura K, Akiyama T. Reliability and Validity of the Musculoskeletal Tumour Society Scoring System for the Upper Extremity in Japanese Patients. Clin Orthop Relat Res 2017; 475: 2253-2259.

6. Strony D, John BS, Brown A, Scot MD, Choong F, Peter BS, et al. Musculoskeletal Infection in Orthopaedic Oncology. J Bone Joint Surg 2019;101(20):e107.

7. Liu B, Tan JC, Wang HL, Wu Z, Yuan ZC, Wei CY. The role of mesh technology with tumour prosthesis reconstruction to reconstruct the extensor mechanism of the knee joint after resection of proximal tibial tumours. J Orthop Surg Res. 2019;14(1):64.

8. Buch RG. Orthopaedic Oncology. Limb Salvage Using Newer Implant Prosthetic Designs. Baylor Univ. Med Center Proceedings 2009; 5(3): 27-39. 